\title{
The role of whole-wheat grain and wheat and rye ingredients on the digestion and fermentation processes in the gut - a model experiment with pigs
}

\author{
Maud Le Gall ${ }^{1,2,3 *}$, Anja Serena ${ }^{1}$, Henry Jørgensen ${ }^{1}$, Peter Kappel Theil ${ }^{1}$ and Knud Erik Bach Knudsen ${ }^{1}$ \\ ${ }^{1}$ Department of Animal Health, Welfare and Nutrition, Faculty of Agricultural Sciences, Aarhus University, \\ DK-8830 Tjele, Denmark \\ ${ }^{2}$ Present address: INRA, UMR1079 Systèmes d'Elevage Nutrition Animale et Humaine, F-35590 Saint-Gilles, France \\ ${ }^{3}$ Agrocampus Ouest, UMR1079 Systèmes d'Elevage Nutrition Animale et Humaine, F-35000 Rennes, France \\ (Received 12 January 2009 - Revised 9 June 2009 - Accepted 11 June 2009 - First published online 27 July 2009)
}

The effect of wheat and rye breads made from white wheat flour with added refined fibre (WFL), whole-wheat grain, wheat aleurone flour (WAF) or rye aleurone flour (RAF) on digestion and fermentation processes in the gut was studied in a model experiment with pigs. The diets were similar in dietary fibre (DF) but differed in arabinoxylan (AX) content and composition. Twenty pigs were fed the breads three times daily $(08.00,13.00$ and 18.00 hours) and the digesta collected through a T-cannula for two successive periods (breakfast: $8.00-13.00$; lunch: 13.00-18.00 hours). Faeces were collected for $24 \mathrm{~h}$ and caecal and colonic contents at slaughter. The rigid nature of the aleurone cell walls encapsulated nutrients, which resulted in reduced $(P<0.01)$ digestibility of protein (WAF and RAF breads) and fat (RAF bread). For the RAF bread, the digestibility of starch was also lower $(P<0 \cdot 001)$ than of the wheat-based diets primarily due to the higher intestinal viscosity. The DF composition had an impact on $(P<0.001)$ the site for fibre degradation in the large intestine. Thus, AX of the WAF bread, with the lowest degree of substitution, were fermented as much in the caecum as in the colon, whereas AX of the RAF bread, with an intermediary degree of substitution, were mainly fermented in the caecum. The WFL bread, rich in cellulose, was fermented more distally. Fermentation of experimental breads in the large intestine had no effect $(P>0 \cdot 05)$ on the production of metabolites, except for butyrate which was higher $(P<0 \cdot 01)$ after the WAF bread consumption.

Arabinoxylans: Dietary fibre: Aleurone cell walls: Whole grains: Fat: Starch

Epidemiological studies suggest that whole-grain consumption reduces the risk of developing several Western diseases such as CVD, certain types of cancers like breast and colon cancer and type 2 diabetes $^{(1,2)}$. In most Western countries, wholegrain cereals (wheat, rye, oat, etc) represent a major source of dietary fibre (DF). Cereal and whole-grain consumption, however, has decreased dramatically over the last century. In addition, cereals are mainly consumed as refined products with lower DF contents, and today, the daily DF intake remains inferior to the recommendations. Thus, the development of new cereal-based products rich in DF would be useful. An ingredient rich in DF is the aleurone-rich fraction, which is an important by-product of white flour production (by roller milling) ${ }^{(3,4)}$.

To date, the effects of wholegrain fibres on digestion and fermentation in the gastrointestinal tract (GIT) have been described extensively, whereas the effects of breads enriched in aleurone fibres are not well known. Indeed, DF influences several physiological aspects depending on its chemical structure (composition and degree of polymerisation) and its physico-chemical properties (solubility and water-binding capacity). DF influences digestion and absorption processes along the $\mathrm{GIT}^{(5)}$; in the small intestine, soluble fibres raise the luminal viscosity and increases the water-binding capacity of digesta, thereby lowering the rate at which glucose is delivered to the enterocytes ${ }^{(6)}$. In the large intestine, insoluble fibres (for example, cellulose and lignin), resistant to fermentation, are associated with a dilution of intestinal components by an increase of faecal mass and a reduction of transit time ${ }^{(7)}$. Soluble fibres are highly fermentable, generating great quantities of SCFA and causing lowering of intraluminal colonic $\mathrm{pH}$, which are considered beneficial for intestinal health. Butyrate, one of the specific SCFA, is an important energy source for intestinal epithelial cells and plays a role in the maintenance of colonic homeostasis by acting on a variety of colonic mucosal functions ${ }^{(8)}$. In addition, butyrate may promote satiety ${ }^{(8)}$.

The quantitatively most important DF in wheat and rye are NSP in the form of arabinoxylans (AX), while cellulose, $\beta$-glucan and lignin constitute the remaining part of fibres. Moreover, AX, $\beta$-glucan and cellulose are present in different proportions in the endosperm, aleurone and pericarp/testa tissues of the grain ${ }^{(9)}$. The aleurone layer, which has thick and unlignified cell walls, contains $650 \mathrm{~g} \mathrm{AX}$ and $310 \mathrm{~g}$

Abbreviations: AX, arabinoxylan; DF, dietary fibre; GIT, gastrointestinal tract; RAF, rye aleurone flour; WAF, wheat aleurone flour; WFL, wheat flour; WWG, whole-wheat grain.

* Corresponding author: Dr Maud Le Gall, fax +33 223485080, email Maud.LeGall@rennes.inra.fr 
$\beta$-glucan $/ \mathrm{kg}^{(10)}$ and potentially degradable encapsulated proteins and lipids. AX represent a heterogenic group of polysaccharides of high molecular weight which are comprised of xylan backbones substituted to various degrees with arabinose residues ${ }^{(3)}$ and $\beta$-glucans are mixed linked (1-3;1-4)-D-glucan. The AX structure varies between different parts of the grain and according to botanical origin. In particular, the $\mathrm{AX}$ of the aleurone layer has a low degree of substitution in comparison with the AX of the pericarp/ testa. While the structure of rye $A X$ is similar to that of wheat AX, the occurrence of the differently bound arabinofuranosyl residues is different between these cereals ${ }^{(11)}$. The structural characteristics of fibres have important implications for digestion and fermentation ${ }^{(12)}$, but comparisons according to the botanical origin of aleurone fibres have not been yet investigated.

It is hypothesised that the DF from aleurone cells influences digestion events and fermentation processes in a different way as compared with fibre from refined sources or from the whole grain. It is further hypothesised that the digestibility in the small intestine will be influenced by the meal due to different time periods since last feeding. This was investigated by feeding ileal-cannulated pigs iso-fibrous breads prepared from (1) white wheat flour with added purified fibre rich in cellulose, (2) whole-wheat grain, (3) the aleurone-rich fraction of wheat and (4) the aleurone-rich fraction of rye. The pigs were used as models for humans to study the intestinal digestion in single-stomached animals, providing easy access to sample digesta from various segments of the GIT either via cannulation or slaughtering ${ }^{(13,14)}$.

\section{Materials and methods}

\section{Breads}

The breads were made of standard white wheat flour (WFL), whole-wheat grain (WWG), wheat aleurone-rich flour (WAF) and rye aleurone-rich flour (RAF). The WFL and WWG breads were produced at Holstebro Technical College (Holstebro, Denmark) and the WAF and RAF breads were baked in a local bakery (Konditor-Bager Ørum, Denmark). The ingredients for the WFL bread were white wheat flour (Triticum aestivum, cv Tiger), purified wheat fibres (Vitacel R200; J. Rettenmaier and Söhne GmbH, Rosenberg, Germany), rapeseed oil, sugar, salt, wheat gluten (LCH A/S, Frederiksberg, Denmark) and yeast. In the WWG, WAF and RAF breads, wholegrain wheat (German Federal Research Centre for Nutrition and Food (BFEL), Karlsruhe, Germany), wheat aleurone (Bühler AG, Uzweil, Switzerland) and rye aleurone-rich flour (Raisio plc, Raisio, Finland) replaced the white wheat flour and purified wheat fibre on an iso-DF basis. After production, breads were cut into pieces and mixed with chromic oxide, an indigestible marker. After weighing, meal portions were frozen at $-20^{\circ} \mathrm{C}$ until consumption. The four breads were balanced with regard to starch, protein, fat, energy and DF, but they varied in characteristics of DF (for dietary ingredients and composition, see Table 1). Thus, the arabinose:xylose ratio varied largely among the diets. The feed supply corresponded approximately to $80 \%$ of the energy ingested by pigs when they were fed ad libitum for their physiological state (body weight $64.9 \pm 1.2 \mathrm{~kg}$ ).

\section{Experimental design and pigs}

Housing and rearing were in compliance with the guidelines of the Danish Ministry of Justice and regulations for the humane care and use of animals in research (The Danish Ministry of Justice, Animal Testing Act (Consolidation Act no. 726 of 9 September 1993 , as amended by act no. 1081 of 20 December 1995)). Furthermore, the Danish Animal Experimentation Inspectorate approved the study protocols and supervised the experiment. The health of the animals was monitored, and no illness was observed. Twenty crossbreed (Duroc $\times$ Landrace $\times$ Yorkshire) growing female pigs (Aarhus University, Faculty of Agricultural Sciences, Swine Herd, Foulum, Denmark) were used for the experiment in a repeated-block experiment (two pigs per treatment for the two first blocks and one per treatment for the third block). All pigs were fitted with a T-cannula in the ileum about $15 \mathrm{~cm}$ anterior to the ileal-caecal junction and given antibiotics (Streptocillin) for $3 \mathrm{~d}$ post-surgery (body weight at surgery: $64.9 \pm 1.2 \mathrm{~kg}$ ). Before the surgery, the pigs were fed a diet with a low DF level. After a $10 \mathrm{~d}$ recovery period from the surgery, the pigs were fed on the same diet before the surgery and then, from day 7 to day 10 , they were gradually introduced to the experimental diets. The pigs were fed three times daily at 08.00 (breakfast), 13.00 (lunch) and 18.00 hours (dinner) with an amount of 40,40 and $20 \%$ of the daily supply, thereby mimicking the diurnal variation in cereal intake experienced by humans. Thus, when pigs received breakfast and lunch meals, the time interval since last feeding was 14 and $5 \mathrm{~h}$, respectively; the expected impact of time since last feeding therefore became more pronounced due to differences in portion size at the previous meal (20\% of daily allowance at dinner, $40 \%$ at breakfast). Ileal digesta were collected on days 15 and 17 during two consecutive periods (08.0013.00 hours, breakfast period; $13.00-18.00$ hours, lunch period) after feeding and a few drops of $0.2 \%$ sodium azide were added to eliminate further bacterial activity. Ileal digesta were subsampled for further analysis. In order to obtain more representative samples, ileal digesta samples intended for digestibility investigation were pooled across collections from the same period for the two collection days within each pig. A part was frozen at $-20^{\circ} \mathrm{C}$ and freeze-dried until analysis and a second part was immediately separated by centrifugation into a liquid and a solid phase. Faeces were collected for $24 \mathrm{~h}$ from 08.00 hours on the morning of day 20. On day 22 or 23, the pigs were slaughtered $14 \mathrm{~h}$ post-feeding. The GIT was immediately removed and the caecum and colon were separated. Caecal and colon contents were collected, weighed and frozen at $-20^{\circ} \mathrm{C}$ until analysis.

\section{Analytical methods}

All chemical analyses were performed in duplicate and physico-chemical analyses in triplicate. Chromic oxide, lactic acid, SCFA and viscosity determinations were performed on wet materials; other analyses were performed on freeze-dried materials. The DM contents of diets, digesta and faeces were determined by drying to constant weight at $103^{\circ} \mathrm{C}$ (practically about $20 \mathrm{~h}$ ) and protein $(\mathrm{N} \times 6.25)$ was 
Table 1. Ingredients and chemical and physico-chemical characteristics of the experimental breads

\begin{tabular}{|c|c|c|c|c|}
\hline & WFL & WWG & WAF & RAF \\
\hline \multicolumn{5}{|l|}{ Ingredients $(\mathrm{g} / \mathrm{kg})$} \\
\hline Vitacel R200 (99.5\% cellulose) ${ }^{*}$ & 69 & - & - & - \\
\hline Standard wheat flour & 711 & - & - & - \\
\hline Whole-wheat grain & - & 813 & - & - \\
\hline Wheat aleurone $\dagger$ & - & - & 214 & - \\
\hline Rye aleuroneł & - & - & - & 365 \\
\hline Wheat starch§ & - & - & 516 & 359 \\
\hline Wheat gluten\| & 59 & 36 & 116 & 116 \\
\hline Rapeseed oil & 86 & 76 & 79 & 85 \\
\hline Sugar & 15 & 15 & 15 & 15 \\
\hline Vitamin-mineral mixtureq & 40 & 40 & 40 & 40 \\
\hline Baker's yeast & 15 & 15 & 15 & 15 \\
\hline \multicolumn{5}{|c|}{ Determined chemical composition ( $\mathrm{g} / \mathrm{kg} \mathrm{DM})$} \\
\hline DM (g/kg feed) & 639 & 654 & 704 & 691 \\
\hline Ash & 36.5 & 43.2 & $57 \cdot 7$ & 41.0 \\
\hline Protein $(\mathrm{N} \times 6.25)$ & $168 \cdot 1$ & 173.4 & $176 \cdot 6$ & $172 \cdot 5$ \\
\hline Fat & 128.4 & $137 \cdot 2$ & 134.0 & $145 \cdot 6$ \\
\hline Sugars & $13 \cdot 0$ & $22 \cdot 1$ & $14 \cdot 8$ & $26 \cdot 9$ \\
\hline Fructans & 1.7 & 2.9 & 1.5 & $10 \cdot 3$ \\
\hline Starch & $513 \cdot 0$ & $505 \cdot 8$ & 469.9 & $505 \cdot 0$ \\
\hline Total dietary fibre (NSP + lignin) & $124 \cdot 7$ & $124 \cdot 2$ & $125 \cdot 1$ & $120 \cdot 0$ \\
\hline Total NSP & $115 \cdot 0$ & $102 \cdot 5$ & $102 \cdot 6$ & 94.4 \\
\hline Soluble NSP & $14 \cdot 3$ & $22 \cdot 7$ & $12 \cdot 7$ & $29 \cdot 0$ \\
\hline Cellulose & 65.9 & $17 \cdot 4$ & $14 \cdot 1$ & $11 \cdot 8$ \\
\hline Total $\beta$-glucan & 0.9 & 3.6 & $7 \cdot 6$ & 9 \\
\hline Soluble $\beta$-glucan & 0 & 0.1 & 0.3 & $2 \cdot 4$ \\
\hline Total arabinoxylans & $26 \cdot 1$ & $60 \cdot 7$ & $61 \cdot 8$ & $50 \cdot 4$ \\
\hline Soluble arabinoxylans & $11 \cdot 0$ & $17 \cdot 1$ & $8 \cdot 8$ & $19 \cdot 2$ \\
\hline Ara: $X y l^{* *}$ & 0.42 & 0.65 & 0.48 & 0.5 \\
\hline Klason lignin & $9 \cdot 7$ & $21 \cdot 7$ & $22 \cdot 5$ & $25 \cdot 6$ \\
\hline Viscosity $(\mathrm{mPa} \times \mathrm{s})$ & $1 \cdot 30$ & 1.42 & 0.95 & $2 \cdot 2$ \\
\hline Water-retention capacity (g/g DM) & $2 \cdot 6$ & $2 \cdot 6$ & $2 \cdot 8$ & $2 \cdot 3$ \\
\hline
\end{tabular}

WFL, wheat flour bread with cellulose; WWG, whole-wheat grain bread; WAF, wheat aleurone flour bread; RAF, rye aleurone flour bread.

*Vitacel R200 (J Rettenmaier and Söhne GmbH, Rosenberg, Germany).

† Leuron ${ }^{\circledR}$ ASP02 (Bühler AG, Uzweil, Switzerland).

‡Fibre-rich rye flour (Raisio plc, Raisio, Finland).

$\S$ Wheat starch 'Foodstar' (LCH A/S, Frederiksberg, Denmark).

\|V Vital wheat gluten (LCH A/S, Frederiksberg, Denmark).

ๆ Supplying (per $\mathrm{kg}$ bread): retinol, $660 \mu \mathrm{g}$; cholecalciferol, $12.5 \mu \mathrm{g} ; \alpha$-tocopherol, $30 \mathrm{mg}$; menadione, $11 \mathrm{mg}$; thiamin, $1 \mathrm{mg}$; riboflavin, $2 \mathrm{mg}$; d-pantothenic acid, $5.5 \mathrm{mg}$; niacin, $11 \mathrm{mg}$ (available); biotin, $27.5 \mu \mathrm{g}$; cyanocobalamin, $11 \mu \mathrm{g}$; pyridoxine, $1.65 \mathrm{mg}$; $\mathrm{Fe}, 25 \mathrm{mg}$; Cu, $10 \mathrm{mg}$; $\mathrm{Zn}, 40 \mathrm{mg}$; $\mathrm{Mn}, 13.9 \mathrm{mg}$; Co, $0.15 \mathrm{mg}$; I, $0.01 \mathrm{mg}$; Se, $0.15 \mathrm{mg}$ and as a carrier, $\mathrm{Ca}_{2}\left(\mathrm{PO}_{4}\right)_{3}$, $\mathrm{K}_{2} \mathrm{PO}_{3}, \mathrm{NaCl}, \mathrm{CaCO}_{3}$ and maize (Solivit Mikro 106; Løvens Kemiske Fabrik, Vejen, Denmark).

${ }^{* *}$ Ratio between the arabinose and the xylose residue amounts in ileal digesta.

determined by the Dumas method ${ }^{(15)}$. Ash was analysed by an AOAC method ${ }^{(16)}$, fat (hydrochloric acid-fat) was extracted according to the Bligh \& Dyer method ${ }^{(17)}$ after acid hydrolysis and chromic oxide was determined using the method of Schürch et al. ${ }^{(18)}$. Ileal and faecal samples were analysed for products of fermentation (acetate, propionate, butyrate, branched-chain fatty acids, formate and lactic acid) contents by GC as described in detail by Jensen et al. ${ }^{(19)}$. Total starch was analysed by the enzymic-colorimetric method of Bach Knudsen ${ }^{(9)}$, and total and insoluble $\beta$-glucan determined by the enzymic-colorimetric method of McCleary \& Glennie-Holmes $^{(20)}$. Soluble $\beta$-glucan was determined as the difference between total $\beta$-glucan and insoluble $\beta$-glucan after extraction of the soluble $\beta$-glucan with water. Total NSP and their constituent sugars were determined as alditol acetates by GLC for neutral sugars and by a colorimetric method for uronic acids using a modification of the Uppsala procedure ${ }^{(21)}$ and the procedure of Englyst et al. ${ }^{(22)}$ as described by
Bach Knudsen ${ }^{(9)}$. Content of cellulose was calculated as:

Cellulose $=\mathrm{NSP}_{\text {glucose }\left(12 \mathrm{M}-\mathrm{H}_{2} \mathrm{SO}_{4}\right)}-\mathrm{NSP}_{\text {glucose }\left(2 \mathrm{M}-\mathrm{H}_{2} \mathrm{SO}_{4}\right)}$.

AX were calculated as:

$$
\mathrm{AX}=\text { arabinose }+ \text { xylose. }
$$

Soluble NSP was calculated as:

$$
\text { Soluble NSP }=\text { total NSP }- \text { insoluble NSP. }
$$

Klason lignin in the breads was measured gravimetrically as the residue resistant to hydrolysis with $2 \mathrm{M}-\mathrm{H}_{2} \mathrm{SO}_{4}^{(21)}$.

Viscosity was measured in extracts of breads and ileal digesta following the procedure of Johansen et al. ${ }^{(23)}$. Centrifugation of diet extracts and digesta samples remove materials that contribute to the rheological behaviour 
of digesta; thus the values can be considered to be only indicative. Values of apparent viscosity at shear rate 30/s are reported. The procedure for water-retention capacity by centrifugation in breads followed essentially that of Canibe $\&$ Bach Knudsen $^{(24)}$.

\section{Calculations}

The apparent digestibility coefficients of nutrients and NSP sugars at the ileal level, in the caecum, in the colon and in the faeces were calculated relative to the $\mathrm{Cr}_{2} \mathrm{O}_{3}$ concentration, according to the following equations ${ }^{(25)}$ :

$$
\text { Digestibility of } \mathrm{X}=1-\frac{\mathrm{Cr}_{2} \mathrm{O}_{3 \text { (bread })} \times \mathrm{X}_{(\mathrm{GIT})}}{\mathrm{Cr}_{2} \mathrm{O}_{3(\mathrm{GIT})} \times \mathrm{X}_{(\text {bread })}} \text {, }
$$

where $\mathrm{X}$ is the concentration of the component determined in the diet and in a specific part of the GIT, for example, the ileum, caecum, colon or faeces, and $\mathrm{Cr}_{2} \mathrm{O}_{3 \text { (bread) }}$ and $\mathrm{Cr}_{2} \mathrm{O}_{3 \text { (GIT) }}$ are the concentrations of chromic oxide in the breads and the gastrointestinal material, respectively.

The mean transit time in the caecum and colon was calculated as:

$$
\text { Mean transit time }=\frac{\mathrm{Cr}_{2} \mathrm{O}_{3(\mathrm{GIT})} \times 24}{\mathrm{Cr}_{2} \mathrm{O}_{3(\text { day })}},
$$

where $\mathrm{Cr}_{2} \mathrm{O}_{3 \text { (GIT) }}$ is the amount of chromic oxide determined in the specific part of the GIT, caecum and colon, and $\mathrm{Cr}_{2} \mathrm{O}_{3 \text { (day) }}$ is the amount of chromic oxide ingested for $24 \mathrm{~h}$.

\section{Statistical analysis}

Two types of analyses were carried out. The first type of analysis, concerning the analysis of data, was accomplished using the Mixed procedure of SAS (SAS Institute, Inc., Cary, NC, USA). The effects of breads, meals or intestinal segments on the digestibility of macronutrients and NSP, and on concentrations of metabolites (formate, lactic acid), SCFA (acetate, propionate, butyrate, valerate, caprionate) and branched-chain fatty acids (iso-butyrate, isovalerate) in fresh intestinal contents were analysed using the following normal Mixed model:

$$
\mathrm{X}_{(\mathrm{ijk})}=\mu+\alpha_{(\mathrm{i})}+\beta_{(\mathrm{j})}+\gamma_{(\mathrm{k})}+\alpha \gamma_{(\mathrm{ik})}+v_{(\mathrm{ijk})}+\mathrm{e}_{(\mathrm{ijk})},
$$

where $\alpha_{(i)}$ is the bread ( $\mathrm{i}=$ WFL, WWG, WAF or RAF); $\beta_{(j)}$ is the block $(j=1,2$ or 3$) ; \gamma_{(k)}$ is the meal $(k=$ breakfast, lunch) or the intestinal segment ( $\mathrm{k}=$ caecum, colon), and $\alpha \gamma_{(\mathrm{ik})}$ is the two-factorial interaction between bread and meal (or bread $x$ intestinal segment). The term $v_{(\mathrm{ijk})}$ accounted for repeated measurements being performed on the same pig within a block either at different meals or at different intestinal segments, and $\mathrm{e}_{(\mathrm{ijk})}$ describes the random error. The level of significance was set at $P<0.05$, whereas tendencies were reported when $0 \cdot 05 \leq P \leq 0 \cdot 10$.

The second type of analysis compared treatment effects (i.e. bread) in the faeces. This was accomplished by a simple ANOVA based on the model:

$$
X_{(i j)}=m+\alpha_{(i)}+\beta_{(j)}+\varepsilon_{(i, j)},
$$

where $\alpha_{(i)}$ denotes the breads ( $i=$ WFL, WWG, WAF or $\mathrm{RAF}) ; \beta_{(\mathrm{j})}$ denotes the block $(\mathrm{j}=1,2$ or 3$)$ and $\varepsilon_{(\mathrm{i}, \mathrm{j})}$ accounts for unexplained variation.

\section{Results}

\section{Dietary fibre characteristics of the breads}

The four experimental breads were formulated to be similar in macronutrients and to provide DF with different characteristics (Table 1). The concentration of starch was $505-513 \mathrm{~g} / \mathrm{kg} \mathrm{DM}$ in the WFL, WWG and RAF breads but was lower in the WAF bread $(469 \mathrm{~g} / \mathrm{kg} \mathrm{DM})$. The concentration of total DF was $120-125 \mathrm{~g} / \mathrm{kg} \mathrm{DM}$ in the four breads, but the proportion of DF polymers (cellulose, AX, $\beta$-glucan and lignin) varied among the breads. The WFL bread had a high proportion of cellulose, whereas the three other breads (WWG, WAF and RAF) had a high proportion of AX, and Klason lignin. The RAF bread had the highest content of soluble components in the form of AX and $\beta$-glucan. The WWG bread and the WAF bread differed by their soluble contents, which were lower in the WAF bread than in the WWG bread and mainly in the form of AX. The arabinose:xylose ratio was $0.42-0.65$ in the four breads. Viscosity varied among the breads, with the highest value for the RAF bread and the lowest for the WAF bread. Water-retention capacity was comparable for the four breads.

\section{Small intestine}

The flow of dry solids was highest $(P<0 \cdot 01)$ when feeding the WAF bread and lowest when feeding the WWG bread, with the two other breads in between (Table 2). The flow was higher $(P<0 \cdot 001)$ after the breakfast feeding than after the lunch feeding. The apparent viscosity of ileal digesta was 2- to 3-fold higher $(P<0.001)$ after consumption of the RAF bread than after the three wheat-based breads (Table 2). No differences were observed among the WFL, the WWG and the WAF groups or between breakfast and lunch meals.

The digestibility of protein was lower $(P<0.001)$ when feeding the two aleurone breads (WAF and RAF) than after the WFL and the WWG breads. For protein, digestibility was also lower $(P<0.001)$ after the breakfast feeding than after the lunch feeding. The digestibility of fat was lower $(P<0.05)$ for the RAF bread than the WFL bread, with the other two breads falling in between. The digestibility of starch was approximately 1 percentage unit lower $(P<0 \cdot 001)$ in the RAF group than in the three wheat-based groups for which no differences were observed. The digestibilities of total NSP and AX were higher $(P<0.05)$ when feeding the WWG bread compared with the other three diets. For insoluble NSP and insoluble AX, the digestibility of the WWG bread was higher $(P<0.001)$ than of the aleurone breads (WAF, RAF). For cellulose, digestibility was the lowest $(P<0.01)$ for the RAF bread. For $\beta$-glucan, the digestibility was the lowest for the WAF bread $(P<0 \cdot 01)$. $\beta$-Glucan was the only NSP component for which its digestibility increased $(P<0 \cdot 01)$ between breakfast and lunch meals.

Total polysaccharides represented $429-564 \mathrm{~g} / \mathrm{kg}$ dry solid, with the highest values $(P<0.001)$ in digesta from pigs fed 
Table 2. Effect of dietary fibre (NSP) composition and meal on the flow of dry material, viscosity of ileal digesta, ileal digestibility of nutrients and NSP components, composition of NSP components and on concentration of SCFA in ileal soluble digesta for pigs fed breakfast at 08.00 hours and lunch at 13.00 hours

(Least square means with residual standard errors of ANOVA for five pigs per bread)

\begin{tabular}{|c|c|c|c|c|c|c|c|c|c|c|}
\hline & \multicolumn{4}{|c|}{ Bread } & \multirow[b]{2}{*}{ SEM } & \multicolumn{2}{|c|}{ Meal $^{*}$} & \multirow[b]{2}{*}{ SEM } & \multicolumn{2}{|c|}{$P+$} \\
\hline & WFL & WWG & WAF & RAF & & Breakfast & Lunch & & Bread & Meal \\
\hline Dry solids (g/h) & $13 \cdot 6^{a, b}$ & $12 \cdot 4^{\mathrm{b}}$ & $15 \cdot 2^{\mathrm{a}}$ & $13 \cdot 7^{\mathrm{a}, \mathrm{b}}$ & 0.5 & $14 \cdot 4^{\mathrm{a}}$ & $13 \cdot 1^{\mathrm{b}}$ & 0.3 & 0.010 & $<0.001$ \\
\hline Viscosity $(\mathrm{mPa} \times \mathrm{s})$ & $1.7^{\mathrm{b}}$ & $1 \cdot 7^{\mathrm{b}}$ & $1.4^{\mathrm{b}}$ & $4 \cdot 7^{\mathrm{a}}$ & 0.4 & $2 \cdot 6$ & $2 \cdot 2$ & 0.3 & $<0.001$ & 0.193 \\
\hline \multicolumn{11}{|l|}{ Digestibility } \\
\hline Protein $(\mathrm{N} \times 6.25)$ & $0.880^{\mathrm{a}}$ & $0.863^{\mathrm{a}}$ & $0.815^{\mathrm{b}}$ & $0.811^{\mathrm{b}}$ & 0.008 & $0.831^{b}$ & $0.854^{a}$ & 0.004 & $<0.001$ & $<0.001$ \\
\hline Fat & $0.897^{\mathrm{a}}$ & $0.875^{a, b}$ & $0.853^{a, b}$ & $0.835^{b}$ & 0.013 & 0.862 & 0.869 & 0.007 & 0.018 & 0.121 \\
\hline Starch & $0.980^{a}$ & $0.984^{a}$ & $0.983^{\mathrm{a}}$ & $0.973^{\mathrm{b}}$ & 0.001 & 0.980 & 0.980 & 0.001 & $<0.001$ & 0.704 \\
\hline Total NSP & $0.090^{b}$ & $0.275^{\mathrm{a}}$ & $0.044^{b}$ & $-0.004^{b}$ & 0.045 & 0.090 & 0.111 & 0.025 & 0.002 & 0.405 \\
\hline Insoluble NSP & $0.128^{a, b}$ & $0.213^{\mathrm{a}}$ & $0.039^{b, c}$ & $-0.044^{c}$ & 0.025 & 0.080 & 0.088 & 0.019 & $<0.001$ & 0.755 \\
\hline Soluble NSP & -0.181 & 0.495 & 0.028 & 0.085 & 0.194 & 0.035 & 0.178 & 0.102 & 0.135 & 0.069 \\
\hline Cellulose & $0 \cdot 120^{a, b}$ & $0 \cdot 191^{a}$ & $0.080^{a, b}$ & $0.045^{b}$ & 0.026 & 0.122 & 0.096 & 0.019 & 0.008 & 0.328 \\
\hline$\beta$-Glucan & $0.657^{\mathrm{a}}$ & $0.727^{\mathrm{a}}$ & $0.414^{\mathrm{b}}$ & $0.579^{\mathrm{a}, \mathrm{b}}$ & 0.050 & $0.564^{\mathrm{b}}$ & $0.624^{\mathrm{a}}$ & 0.026 & 0.003 & 0.004 \\
\hline Arabinoxylans & $0.064^{b}$ & $0.281^{a}$ & $0.029^{b}$ & $-0.031^{b}$ & 0.060 & 0.082 & 0.089 & 0.031 & 0.008 & 0.790 \\
\hline Insoluble arabinoxylans & $0.036^{a, b}$ & $0 \cdot 191^{\mathrm{a}}$ & $-0.057^{b, c}$ & $-0.139^{c}$ & 0.041 & -0.008 & 0.023 & 0.026 & $<0.001$ & 0.332 \\
\hline Soluble arabinoxylans & 0.108 & 0.511 & 0.382 & 0.143 & 0.121 & 0.296 & 0.276 & 0.061 & 0.081 & 0.515 \\
\hline Total polysaccharides ( $\mathrm{g} / \mathrm{kg}$ solids) & $564^{a}$ & $429^{\mathrm{b}}$ & $456^{\mathrm{b}}$ & $468^{\mathrm{b}}$ & 20 & $463^{\mathrm{b}}$ & $495^{\mathrm{a}}$ & 24 & 0.001 & 0.014 \\
\hline Soluble NSP ( $\mathrm{g} / \mathrm{kg}$ digesta) & $85^{\mathrm{a}}$ & $64^{\mathrm{a}}$ & $61^{\mathrm{a}}$ & $123^{\mathrm{b}}$ & 16 & 83 & 83 & 16 & 0.039 & 0.897 \\
\hline \multicolumn{11}{|l|}{ Ratios } \\
\hline Ara:Xylł & $0.45^{\mathrm{b}}$ & $0.71^{\mathrm{a}}$ & $0.51^{\mathrm{c}}$ & $0.60^{\mathrm{d}}$ & 0.01 & 0.56 & 0.57 & 0.01 & $<0.001$ & 0.086 \\
\hline Polysaccharides:N§ & $33 \cdot 6^{\mathrm{a}}$ & $20 \cdot 1^{\mathrm{b}}$ & $18.9^{\mathrm{b}}$ & $19 \cdot 5^{\mathrm{b}}$ & 1.6 & $21 \cdot 3^{\mathrm{b}}$ & $24.7^{\mathrm{a}}$ & 0.9 & $<0.001$ & $<0.001$ \\
\hline \multicolumn{11}{|l|}{ Organic acids (mmol/kg digesta) } \\
\hline Lactic acid & 4.6 & 3.7 & 4.3 & $7 \cdot 0$ & 1.4 & $3.4^{\mathrm{b}}$ & $6 \cdot 5^{\mathrm{a}}$ & 0.7 & 0.349 & $<0.001$ \\
\hline Formic acid & $17 \cdot 0^{\mathrm{b}}$ & $22 \cdot 5^{\mathrm{a}, \mathrm{b}}$ & $17 \cdot 9^{a, b}$ & $23 \cdot 8^{a}$ & 1.5 & $18 \cdot 5^{\mathrm{b}}$ & $22 \cdot 2^{\mathrm{a}}$ & 0.9 & 0.009 & 0.002 \\
\hline SCFA & $18.9^{\mathrm{b}}$ & $26 \cdot 8^{\mathrm{a}}$ & $19.7^{\mathrm{b}}$ & $22 \cdot 5^{\mathrm{a}, \mathrm{b}}$ & 2.0 & 21.4 & $22 \cdot 6$ & 1.0 & 0.044 & 0.085 \\
\hline
\end{tabular}

WFL, wheat flour bread with cellulose; WWG, whole-wheat grain bread; WAF, wheat aleurone flour bread; RAF, rye aleurone flour bread.

a,b,c,d Values within a row with unlike superscript letters were significantly different $(P<0.05)$.

* Ileal digesta were collected from 8.00 to 13.00 hours (breakfast) and from 13.00 to 18.00 hours (lunch).

$\dagger$ The bread $\times$ meal interaction was never significant $(P>0.05)$.

$\ddagger$ Ratio between the arabinose and the xylose residue amounts in ileal digesta.

$\S$ Ratio between the total polysaccharides amount (NSP residues and non-digested starch) and the N amount in ileal digesta. 
the WFL bread. The proportion was on average approximately $30 \mathrm{~g} / \mathrm{kg}$ dry solid higher $(P<0.05)$ during collections after lunch than after breakfast (Table 2). In agreement with bread composition, only $15 \%$ of total NSP was soluble in ileal digesta for the wheat-based breads (WFL, WWG and WAF) compared with $28 \%$ for the RAF bread $(P<0 \cdot 001)$. The arabinose:xylose ratio was different $(P<0.001)$ in digesta between the four breads and not influenced $(P=0.086)$ by the meal. The polysaccharide: $\mathrm{N}$ ratio was higher $(P<0.001)$ for the WFL bread than for the three other breads and higher $(P<0.001)$ after lunch than after the breakfast feeding.

The concentration of lactic acid was not influenced by the dietary composition but was higher $(P<0.001)$ during the lunch collection as compared with the breakfast collection. The same was the case for formic acid $(P<0.001)$ but for this metabolite there was also a diet effect $(P<0 \cdot 01)$; the highest concentration was found after feeding the RAF bread and the lowest after feeding the WFL bread. For SCFA, there were no differences between the meals but the concentration was highest $(P<0.05)$ after feeding the WWG bread and lowest after feeding the WFL bread.

\section{Large intestine}

The mean transit time in the caecum was $1.6-4.2 \mathrm{~h}$ and 23.5-56.0 h in the colon (Table 3). Transit time was shortest $(P<0.001)$ in pigs fed on the WWG, WAF or RAF breads as compared with pigs fed on the WFL bread. No difference was observed among the three fibre sources of cereal origin (WWG, WAF or RAF).

The caecal and colonic digestibilities of protein were lower $(P<0 \cdot 001)$ in pigs fed the WAF and the RAF bread than in pigs fed the WFL or the WWG bread while no differences were observed between the WFL and the WWG treatments (Table 3$)$. The digestibility of protein was higher $(P<0.001)$ in the colon than in the caecum, with a marked increase (bread $\times$ segment interaction; $P<0.01$ ) for the WAF and RAF treatments. The caecal digestibility of fat was lower $(P<0 \cdot 001)$ in pigs fed the WAF and the RAF breads than in pigs fed the WFL and WWG bread but it was not changed $(P>0.05)$ along the large intestine for any dietary treatments (interaction; $P>0.05)$. Total NSP was more extensively fermented $(P<0.001)$ in the caecum of pigs fed the RAF bread $(P<0.001)$ compared with the WFL and the WAF breads. However, no difference among dietary treatments was observed in the colon (interaction; $P<0.05$ ). Cellulose digestibility varied largely according to the dietary treatments. In the caecum, it was lowest in pigs fed the WAF bread $(P<0 \cdot 01)$. While cellulose digestibility was greatly increased $(P<0.001)$ from the caecum to the colon, the values for the WWG and the WAF treatments tended to be lower than those of the WFL and the RAF treatments (interaction; $P=0.07)$. The caecal digestibility of AX was lower $(P<0.001)$ in pigs fed the WWG and the WAF breads than in those fed the WFL and the RAF breads. In the colon, digestibility was highest for the WFL bread and lowest for the WWG bread (interaction; $P<0.001$ ).

The arabinose:xylose ratio was higher $(P<0 \cdot 001)$ in digesta from the caecum than from the ileum for the WWG, WAF and RAF breads but lower for the WFL bread. At the caecal level, the arabinose:xylose ratio was lowest $(P<0 \cdot 001)$ in digesta after feeding the WFL bread, intermediate for the two aleurone (WAF, RAF) breads and highest for the WWG bread. In the colon, the ratio became similar $(P<0.001)$ in digesta from the WWG, WAF and RAF breads where it was substantially lower (interaction; $P<0.05$ ) in digesta from the WFL diet. The polysaccharide:N ratio was lowest $(P<0.001)$ after consumption of the WAF and the RAF breads and highest after WFL bread consumption. The ratio tended to decrease $(P<0 \cdot 01)$ from the caecum to the colon except after consumption of the WWG bread, for which the ratio increased (interaction; $P=0.051$ ).

The concentration of total SCFA or that of the individual acids was not influenced $(P>0.05)$ by the dietary treatment except that of butyrate with the highest $(P<0.01)$ value in digesta of pigs fed the WAF bread. While the concentration of SCFA slightly decreased $(P<0.001)$ between the caecum and the colon, the concentration of branched-chain fatty acids increased $(P<0 \cdot 001)$, especially in pigs fed the WWG or the WAF bread (interaction; $P<0 \cdot 05$ ) (Table 3 ). This was attributed to the increase of the iso-butyrate concentration $(P<0.05$; not shown).

The pool size of intestinal metabolites was approximately $30 \%$ lower $(P<0.05)$ in intestinal samples of pigs fed the WWG, the WAF and the RAF breads than in those of pigs fed the WFL bread. The higher pool size of metabolites in the WFL group was due to the large quantity of cellulose in the caecal and colonic digesta of pigs fed the WFL bread. The pool size of metabolites was greatly increased $(P<0.001)$ from the caecum to the colon for all dietary treatments. While the $\mathrm{pH}$ of intestinal contents was not influenced $(P>0.05)$ by the dietary treatment in the caecum, it was greater $(P<0.001)$ in the colonic samples (interaction; $P<0.05)$ than in the caecal contents when pigs were fed the WWG, the WAF and the RAF breads.

\section{Total intestinal tract}

The faecal excretion of dry solids was highest $(P<0.05)$ after feeding the WWG and WAF breads and lowest after feeding the WFL bread (Table 4). The DM percentage was higher $(P<0 \cdot 001)$ in faeces from the WFL bread than after any of the other breads.

The digestibility of protein and fat was significantly lower $(P<0.01)$ for the two aleurone breads (WAF, RAF) than for the WFL and WWG breads (Table 4). The digestibility of total NSP varied significantly $(P<0 \cdot 01)$, being highest for the RAF bread and lowest for the WWG bread and with the two other breads in between. For the digestibility of cellulose, the highest value was found after feeding the WFL bread, it was intermediate for the RAF bread and lowest for the WWG and WAF breads $(P<0.001)$. In contrast, dietary composition had no influence on the digestibility of AX.

The arabinose:xylose ratio was not significantly different in faecal materials from the WWG, WAF and RAF breads, while it was significantly lower $(P<0.001)$ in faeces from the WFL bread. With regards to the polysaccharide: $\mathrm{N}$ ratios, they were all significantly different $(P<0 \cdot 001)$.

Neither the concentration of total SCFA nor the concentration of the individual acids was influenced by the dietary composition. 
Table 3. Effect of dietary fibre composition on mean transit time, digestibility of nutrients and NSP components and concentration of SCFA and branched-chain fatty acids in different segments of the large intestine for pigs fed breakfast at 08.00 hours and lunch at 13.00 hours

(Least square means with residual standard errors of ANOVA for five pigs per bread)

\begin{tabular}{|c|c|c|c|c|c|c|c|c|c|c|c|c|}
\hline & \multicolumn{4}{|c|}{ Caecum } & \multicolumn{4}{|c|}{ Colon } & \multirow[b]{2}{*}{ SEM } & \multicolumn{3}{|c|}{$P$} \\
\hline & WFL & WWG & WAF & RAF & WFL & WWG & WAF & RAF & & Bread & Segment & Bread $\times$ segment \\
\hline Mean transit time $(\mathrm{h})$ & $4 \cdot 2^{\mathrm{c}}$ & $2 \cdot 7^{\mathrm{c}}$ & $1.6^{\mathrm{c}}$ & $2 \cdot 2^{\mathrm{c}}$ & $56.0^{\mathrm{a}}$ & $28.9^{b}$ & $23.5^{\mathrm{b}}$ & $24 \cdot 6^{\mathrm{b}}$ & 3.8 & 0.001 & $<0.001$ & 0.003 \\
\hline \multicolumn{13}{|l|}{ Diqestibility } \\
\hline Protein $(\mathrm{N} \times 6.25)$ & $0.873^{b, c}$ & $0.843^{c}$ & $0.753^{\mathrm{e}}$ & $0.788^{\mathrm{e}}$ & $0.911^{a, d}$ & $0.888^{b, d}$ & $0.838^{c}$ & $0.848^{c}$ & 0.008 & $<0.001$ & $<0.001$ & 0.008 \\
\hline Fat & $0.907^{\mathrm{a}}$ & $0.874^{\mathrm{a}, \mathrm{c}}$ & $0.797^{b}$ & $0.797^{b}$ & $0.888^{a, c}$ & $0.871^{c}$ & $0.835^{\mathrm{b}, \mathrm{c}}$ & $0.813^{b}$ & 0.013 & $<0.001$ & 0.374 & 0.130 \\
\hline Total NSP & $0.328^{b}$ & $0.453^{\mathrm{a}, \mathrm{b}}$ & $0.352^{b}$ & $0.514^{a}$ & $0.593^{c}$ & $0.583^{\mathrm{c}}$ & $0.661^{\mathrm{c}}$ & $0.730^{\mathrm{c}}$ & 0.030 & $<0.001$ & $<0.001$ & 0.024 \\
\hline Cellulose & $0 \cdot 137^{b}$ & $0 \cdot 104^{b}$ & $-0.153^{c}$ & $0.206^{b}$ & $0.477^{a}$ & $0 \cdot 280^{a, b}$ & $0.319^{\mathrm{a}, \mathrm{b}}$ & $0.562^{\mathrm{a}}$ & 0.058 & 0.001 & $<0.001$ & 0.069 \\
\hline Arabinoxylans & $0.671^{b, c}$ & $0.552^{\mathrm{d}}$ & $0.471^{\mathrm{e}}$ & $0.624^{c}$ & $0.789^{a}$ & $0.620^{\mathrm{C}}$ & $0.704^{\mathrm{b}}$ & $0.738^{\mathrm{b}}$ & 0.013 & $<0.001$ & $<0.001$ & $<0.001$ \\
\hline \multicolumn{13}{|l|}{ Ratios } \\
\hline Ara:Xy| $\left.\right|^{*}$ & $0.23^{\mathrm{c}}$ & $0.91^{a}$ & $0.68^{\mathrm{b}}$ & $0.75^{\mathrm{b}}$ & $0.32^{c}$ & $1.09^{\mathrm{a}}$ & $1.08^{\mathrm{a}}$ & $0.93^{\mathrm{a}}$ & 0.04 & $<0.001$ & $<0.001$ & 0.020 \\
\hline Polysaccharides: $\mathrm{N} \dagger$ & $22 \cdot 8^{\mathrm{a}}$ & $13 \cdot 1^{\mathrm{b}}$ & $9 \cdot 6^{c}$ & $7 \cdot 8^{\mathrm{d}}$ & $19 \cdot 5^{a}$ & $14 \cdot 3^{\mathrm{b}}$ & $7 \cdot 6^{\mathrm{d}}$ & $6 \cdot 2^{\mathrm{d}}$ & 0.8 & $<0.001$ & 0.010 & 0.051 \\
\hline \multicolumn{13}{|c|}{ Organic acids (mmol/ $/ \mathrm{kg}$ digesta) } \\
\hline SCFA & $120^{a}$ & $133^{\mathrm{a}}$ & $137^{\mathrm{a}}$ & $130^{\mathrm{a}}$ & $107^{a}$ & $94^{\mathrm{a}, \mathrm{b}}$ & $109^{a}$ & $112^{\mathrm{a}}$ & 8.0 & 0.621 & $<0.001$ & 0.162 \\
\hline Acetate & $84 \cdot 2^{a, b}$ & $87 \cdot 2^{\mathrm{a}}$ & $84.8^{\mathrm{a}}$ & $85 \cdot 8^{a, b}$ & $74 \cdot 2^{a, b}$ & $62 \cdot 0^{\mathrm{b}}$ & $64 \cdot 8^{\mathrm{b}}$ & $70 \cdot 2^{a, b}$ & $5 \cdot 0$ & 0.836 & $<0.001$ & 0.173 \\
\hline Propionate & $27 \cdot 6^{a, b}$ & $32 \cdot 7^{\mathrm{a}}$ & $34 \cdot 3^{\mathrm{a}, \mathrm{b}}$ & $31.5^{\mathrm{a}, \mathrm{b}}$ & $24 \cdot 5^{a, b}$ & $20.4^{\mathrm{b}}$ & $25 \cdot 6^{a, b}$ & $25 \cdot 9^{a, b}$ & 3.7 & 0.834 & $<0.001$ & 0.149 \\
\hline Butyrate & $5.6^{\mathrm{b}}$ & $11 \cdot 3^{\mathrm{a}, \mathrm{b}}$ & $15 \cdot 9^{\mathrm{a}}$ & $11 \cdot 8^{\mathrm{a}, \mathrm{b}}$ & $6.0^{\mathrm{b}}$ & $9 \cdot 2^{a, b}$ & $15 \cdot 5^{\mathrm{a}}$ & $11.9^{\mathrm{a}, \mathrm{b}}$ & 2.0 & 0.009 & 0.574 & 0.759 \\
\hline Branched-chain fatty acids & $1 \cdot 6^{\mathrm{b}}$ & $0.6^{\mathrm{b}}$ & $0.9^{\mathrm{b}}$ & $0.9^{\mathrm{b}}$ & $2 \cdot 1^{a, b}$ & $2 \cdot 7^{\mathrm{a}}$ & $2.5^{\mathrm{a}}$ & $2 \cdot 2^{a, b}$ & 0.3 & 0.716 & $<0.001$ & 0.012 \\
\hline SCFA pool size (mmol) & $40^{\mathrm{c}}$ & $25^{\mathrm{d}}$ & $27^{\mathrm{d}}$ & $30^{\mathrm{d}}$ & $174^{\mathrm{a}}$ & $110^{\mathrm{b}}$ & $129^{b}$ & $122^{\mathrm{b}}$ & $16 \cdot 0$ & 0.040 & $<0.001$ & 0.191 \\
\hline $\mathrm{pH}$ & $6 \cdot 3^{\mathrm{b}}$ & $6.2^{\mathrm{b}}$ & $6.0^{\mathrm{b}}$ & $6 \cdot 1^{\mathrm{b}}$ & $6.2^{\mathrm{b}}$ & $6 \cdot 8^{\mathrm{a}}$ & $6.4^{\mathrm{a}}$ & $6.5^{\mathrm{a}}$ & 0.1 & 0.260 & $<0.001$ & 0.034 \\
\hline
\end{tabular}


Table 4. Effect of dietary fibre composition on faecal flow, digestibility of nutrients and NSP components and concentrations of SCFA and branched-chain fatty acids in faecal digesta from pigs fed the four experimental breads

(Least square means with residual standard errors of ANOVA for five pigs per bread)

\begin{tabular}{|c|c|c|c|c|c|c|}
\hline & WFL & WWG & WAF & RAF & SEM & $P$ \\
\hline Faecal excretion (g DM/h) & $5 \cdot 1^{b}$ & $6 \cdot 2^{a}$ & $6 \cdot 5^{\mathrm{a}}$ & $5 \cdot 9^{\mathrm{a}, \mathrm{b}}$ & 0.3 & 0.049 \\
\hline Faecal DM (\%) & $51 \cdot 0^{\mathrm{a}}$ & $35 \cdot 1^{\mathrm{b}}$ & $39 \cdot 2^{\mathrm{b}}$ & $39.7^{\mathrm{b}}$ & 1.9 & $<0.001$ \\
\hline \multicolumn{7}{|l|}{ Digestibility } \\
\hline Protein $(\mathrm{N} \times 6.25)$ & $0.921^{a}$ & $0.921^{\mathrm{a}}$ & $0.884^{b}$ & $0.880^{b}$ & 0.007 & $<0.001$ \\
\hline Fat & $0.889^{a}$ & $0.873^{\mathrm{a}}$ & $0.849^{b}$ & $0.826^{\mathrm{b}}$ & 0.011 & 0.003 \\
\hline Total NSP & $0.685^{a}$ & $0.599^{b}$ & $0.663^{\mathrm{a}}$ & $0.733^{c}$ & 0.023 & 0.002 \\
\hline Cellulose & $0.635^{\mathrm{a}}$ & $0.267^{b}$ & $0.222^{b}$ & $0.493^{c}$ & 0.060 & $<0.001$ \\
\hline Arabinoxylans & 0.712 & 0.635 & 0.710 & 0.728 & 0.045 & 0.370 \\
\hline \multicolumn{7}{|l|}{ Ratios } \\
\hline Ara:Xyl* & $0.58^{\mathrm{b}}$ & $1 \cdot 11^{\mathrm{a}}$ & $1 \cdot 10^{\mathrm{a}}$ & $0.99^{\mathrm{a}}$ & 0.08 & 0.001 \\
\hline Polysaccharides: $\mathrm{N} \dagger$ & $16 \cdot 9^{b}$ & $19 \cdot 3^{a}$ & $10 \cdot 6^{\mathrm{c}}$ & $7 \cdot 6^{\mathrm{d}}$ & 0.7 & $<0.001$ \\
\hline \multicolumn{7}{|l|}{ Organic acids $(\mathrm{mmol} / \mathrm{kg})$} \\
\hline SCFA & 104 & 71 & 74 & 72 & 12 & 0.248 \\
\hline Acetate & 73.2 & $50 \cdot 3$ & $51 \cdot 0$ & 51.4 & 8.6 & 0.186 \\
\hline Propionate & 19.4 & $14 \cdot 6$ & $14 \cdot 0$ & $11 \cdot 2$ & $2 \cdot 9$ & 0.236 \\
\hline Butyrate & $8 \cdot 8$ & 4.0 & $6 \cdot 6$ & 5.9 & $2 \cdot 2$ & 0.460 \\
\hline Branched-chain fatty acids & 4.2 & $3 \cdot 7$ & 5.9 & $5 \cdot 7$ & $1 \cdot 1$ & 0.335 \\
\hline
\end{tabular}

WFL, wheat flour bread with cellulose; WWG, whole-wheat grain bread; WAF, wheat aleurone flour bread; RAF, rye aleurone flour bread.

flour bread.
$a, b, c, d$ Values within a row with unlike superscript letters were significantly different $(P<0 \cdot 05)$.

${ }^{*}$ Ratio between the arabinose and the xylose residue amounts in ileal digesta.

$\dagger$ Ratio between the total amount of NSP residues and the N amount in faecal digesta.

\section{Discussion}

In the present investigation we provide evidence that the fibres in the aleurone cells from wheat and rye influenced the degradation of protein and fat at all sites of the GIT and that the AX from the aleurone cells was degraded at different rates in the large intestine. These differences, though, had only a minor influence on the fermentation in the large intestine although a higher butyrate production was seen. We also found that the period of fasting only influenced a few of the investigated digestibility and composition parameters at the ileal level. The low protein digestibility found in aleurone-rich bread (formulated with a high content of wheat gluten) could potentially be explained by the high supplementation of wheat gluten, but wheat gluten is normally regarded as highly digestible ${ }^{(26)}$.

\section{Degradation of NSP from wheat and rye breads in the gastrointestinal tract of pigs}

In the present study, $25 \%$ of NSP disappeared in the small intestine when pigs were fed the WWG bread. In contrast, NSP of the WAF and the RAF breads were not degraded at the ileal level but they were in the large intestine. Thus, AX of the RAF bread were easily fermented in the caecum while those of the WAF bread were more slowly fermented in the caecum as well as in the colon. At the ileal level, similar results were obtained in other studies in pigs ${ }^{(7,27,28)}$, where an $80-85 \%$ recovery of NSP in ileal digesta was reported after feeding whole-wheat and rye grains. The results are also consistent with the studies of Bach Knudsen \& Hansen $^{(29)}$ and Glits $\varnothing$ et $a l .{ }^{(7)}$ who reported that the NSP digestibility of wheat aleurone- and rye aleurone-rich bread was -6 and $12 \%$ in the small intestine and 67 and $73 \%$ in the faeces, respectively. The WWG bread contains a large proportion of the easily degradable endosperm cell walls but contains also the aleurone layer and the undegradable lignified pericarp/ testa ${ }^{(29)}$. The endosperm cell walls have a relatively lower proportion of AX than the bran-rich fractions ${ }^{(30,31)}$ and the $\mathrm{AX}$ is more substituted, which makes the $\mathrm{AX}$ more soluble. These characteristics make this type of AX more easily degraded by the microflora in the distal part of the small intestine and in the caecum ${ }^{(29)}$. The arabinose:xylose ratio is an indicator of the AX degradation. Thus, AX of the RAF bread, more substituted than those of the WAF bread, are readily fermented in the caecum whereas the $\mathrm{AX}$ in the WAF bread are almost equally fermented in the caecum as in the colon. Concurrently, the arabinose:xylose ratio increases along the GIT.

Moreover, differences in relative degradation along the large intestine between the two aleurone breads can be explained by the polysaccharides' organisation and linkage to cellulose and lignin in the cell walls. In the WAF bread, the low cellulose digestibility in the caecum is probably due to the tight association between the unbranched segments of $\mathrm{AX}$ and the cellulose microfibrils as suggested by Carpita \& Gibeaut $^{(32)}$ and Glits $\varnothing$ et al. ${ }^{(7)}$. AX is to a large extent degraded in the proximal part (caecum) while cellulose is mostly degraded in the distal part (colon). The lignin, highly undegradable ${ }^{(32)}$, may also alter the degradation of the other NSP components either by physical encapsulation or chemical binding ${ }^{(33)}$. Virtually all the lignin in grains is contained in the pericarp/testa and since the aleurone layer is situated between the endosperm and the pericarp/testa, the presence of lignin in the WAF or RAF breads in the present study probably reflected some contamination with pericarp/ testa cell walls.

While the $\beta$-glucan content is low in the experimental breads and therefore affects the ileal digestibility of total NSP to a minor degree, their degradation is high in the ileum and they totally disappeared in the caecum, in agreement with 
most studies in pigs ${ }^{(29,34)}$. However, the digestibility of $\beta$-glucan of the WAF bread was lower than that of the RAF bread, presumably caused by the lower solubility of $\beta$-glucan in the WAF bread compared with the RAF bread.

\section{Physico-chemical properties of NSP and the digestion processes}

Cereal DF is well known for its impacts on digestion and fermentation processes in the gut ${ }^{(5)}$. In agreement with these results, we observed the lowest ileal digestibility of all macronutrients (protein, fat and starch) in pigs fed the RAF bread. The digestibility of protein was also lower and that of fat tended to be lower in pigs fed the WAF bread. One explanation for the difference in starch digestion may be attributed to the starch structures of wheat which are easily accessible to salivary and pancreatic $\alpha$-amylases in the small intestine $e^{(5,35)}$ whereas the rye starches are more slowly hydrolysed as shown in in vitro studies ${ }^{(36)}$. While starch structure may be responsible for starch digestibility, NSP properties may also have an impact on the degradation and absorption of starch and other macronutrients. In the present study, the RAF bread had more soluble NSP, mainly as soluble AX, which was associated with greater proportions of soluble NSP in the ileal soluble phase of the digesta and with a higher viscosity. This is in agreement with previous studies with similar types of breads ${ }^{(37,38)}$. The high viscosity of intestinal digesta may play a role in the absorption of nutrients in the small intestine ${ }^{(39)}$, thereby reducing glucose delivery to enterocytes. High intestinal viscosity may also hinder emulsification of lipids and the reabsorption of bile acid at the end of the small intestine ${ }^{(40)}$. Indeed, in the present study, the digestibility of fat was about 5 percent units lower after consumption of the RAF bread in the small intestine and it was about 10 percent units lower after consumption of the two aleurone breads in the caecum. For the WAF bread with a low soluble NSP content, the effect on fat digestion was probably due to the higher resistance of aleurone cells to the microbial degradation in the caecum as illustrated also by the lower NSP digestibility when pigs were fed the WAF bread.

\section{Time of fasting and the digestion processes in the small intestine}

The influence of the period of fasting had only a small, although measurable, impact on the digestibility and metabolite parameters. Thus, the flow rate after breakfast was significantly higher than after lunch, which resulted in 6 percent units lower digestibility of $\beta$-glucan and in 2 percent units lower digestibility of protein. The lower digestibility of $\beta$-glucan after breakfast is most likely a consequence of a higher passage rate through the small intestine due to less gut-fill, and the higher passage rate allows for less time for microbial fermentation. This is in agreement with studies which have reported that the digestibility of organic matter, nutrients and/or DF are higher for longer transit time ${ }^{(41)}$. Consistent with this interpretation, the concentration of lactic acid and formic acid was higher after lunch, i.e. a lower passage rate leaves more time for fermentation, than after breakfast. For the other parameters, however, there was no difference.

\section{SCFA production}

The concentrations of fermentation metabolites are comparable with those found in other studies in pigs fed wheat- and ryebased breads ${ }^{(29,42)}$. In agreement with the digestion of NSP reported above, the SCFA concentrations decreased along the large intestine for all dietary treatments. The fermentations of NSP, however, already started in the terminal ileum, peaked in the caecum and declined along the colon except for the WFL bread for which fermentation was high even in the distal part of the colon as pointed out by the high SCFA concentration also in the faeces. Since the degradation of cellulose in the WFL bread was lower than the AX for the three other breads, the SCFA concentration was also lower. The NSP fermentation observed in the terminal ileum may be attributed to the soluble NSP $\left(\beta\right.$-glucan and AX) ${ }^{(43,44)}$ while insoluble NSP were fermented more distally. This may be linked to the structural features of different types of cell walls and their chemical composition, especially the degree of AX substitution. Moreover, the butyrate concentration was higher in the large intestine of pigs fed the WAF bread, presumably because the large proportion of unsubstituted xylose ${ }^{(7)}$ in $\mathrm{AX}$ (illustrated in the lower AX ratio in the WAF bread) makes the AX slowly degradably and because AX can stimulate butyrate production ${ }^{(37,45)}$. Increased butyrate production in the colon has been reported as being beneficial for intestinal health, as butyrate exerts potent effects on a variety of colonic mucosal functions such as inhibition of inflammation and carcinogenesis, reinforcing various components of the colonic defence barrier and decreasing oxidative stress ${ }^{(8)}$.

The mode of NSP fermentation was also reflected in the $\mathrm{pH}$ values, which remained constant after WFL bread consumption while $\mathrm{pH}$ increased from caecum to colon after WWG, WAF and RAF bread consumption. The smallest increase was in the colonic digesta from pigs fed the aleurone breads (WAF and RAF), indicating that fermentation occurred in the colon as much as in the caecum. As the low $\mathrm{pH}$ values in the distal large intestine are expected to play a role in the protection against colon cancer ${ }^{(46)}$, it appeared here that aleurone breads are more efficient to ensure these properties ${ }^{(7)}$. In contrast to the WWG bread, the aleurone breads provided more $\mathrm{AX}$ to be degraded in the colon due to their low degree of substitution ${ }^{(7)}$.

\section{Conclusions}

In the present study, we report that the experimental breads, differing mainly by their AX contents and structure, had significant influence of the digestibility of nutrients and NSP components at the terminal ileum and in the large intestine but had no effect on the production of metabolites in the large intestine, except on the butyric acid production. The rigid nature of the aleurone cell walls was responsible for the reduced digestibility of protein and fat (RAF bread) and protein (WAF bread). The soluble fibre in the RAF bread was responsible for the higher intestinal viscosity and is the likely cause for the lower digestibility of starch than of the wheat-based breads. The DF composition had an impact on the site for its degradation in the large intestine. Thus, AX of the RAF bread were primarily fermented in the caecum, $\mathrm{AX}$ of the WAF bread as much in the colon as in the 
caecum, whereas the fibres in the WFL bread, rich in cellulose, were fermented in the more distal locations of the large intestine. Finally, only the fermentation of the AX of the WAF bread was able to enhance the butyrate production.

\section{Acknowledgements}

The authors thank Kirsten Østergaard, Winnie Østergaard Thomsen, Benny Thomassen, Kathrine Høirup Hansen, Mie Lilleris Nielsen and Lisbeth Märcher for technical assistance. The financial support of the European Union for the project 'HealthGrain' (contract number FP6-514008) is greatly acknowledged. The authors are solely responsible for the work described in this article, and their opinions are not necessarily those of the European Union.

K. E. B. K. was responsible for project development. A. S., P. K. T. and H. J. conducted the nutritional experiments in pigs. M. L. G. was responsible for the analyses. M. L. G. was responsible for generating statistical analyses. M. L. G., P. K. T. and K. E. B. K. were responsible for drafting the manuscript and M. L. G. is the corresponding author.

There are no conflicts of interest.

\section{References}

1. Jacobs DR Jr, Marquart L, Slavin J, et al. (1998) Whole-grain intake and cancer: an expanded review and meta-analysis. Nutr Cancer 30, 85-96.

2. Marquart L, Jacobs DR Jr \& Slavin J (2000) Whole grains and health: an overview. J Am Coll Nutr 19, 289S-290S.

3. Fincher GB \& Stone BA (1986) Cell walls and their components in cereal grain technology. Advances in Cereal Science and Technology VIII, pp. 207-295 [Y Pomeranz, editor]. St Paul, MN: American Association of Cereal Chemists.

4. Hemery Y, Rouau X, Lullien-Pellerin V, et al. (2007) Dry processes to develop wheat fractions and products with enhanced nutritional quality. J Cereal Sci 46, 327-347.

5. Cummings JH \& Englyst HN (1995) Gastrointestinal effects of food carbohydrate. Am J Clin Nutr 61, 938S-994S.

6. Ellis PR, Roberts FG, Low AG, et al. (1995) The effect of highmolecular-weight guar gum on net apparent glucose absorption and net apparent insulin and gastric inhibitory polypeptide production in the growing pig: relationship to rheological changes in jejunal digesta. Br J Nutr 74, 539-556.

7. Glitsø LV, Brunsgaard G, Højsgaard S, et al. (1998) Intestinal degradation in pigs of rye dietary fibre with different structural characteristics. Br J Nutr 80, 457-468.

8. Hamer HM, Jonkers D, Venema K, et al. (2008) Review Article: the role of butyrate on colonic function. Aliment Pharm Therap 27, 104-119.

9. Bach Knudsen KE (1997) Carbohydrate and lignin contents of plant materials used in animal feeding. Anim Feed Sci Tech 67, 319-338.

10. Bacic A \& Stone BA (1981) Isolation and ultrastructure of aleurone cell walls from wheat and barley. Funct Plant Biol 8, 453-474.

11. Gebruers K, Dornez E, Danuta B, et al. (2008) Variation in the content of dietary fiber and components thereof in wheats in the Healthgrain diversity screen. J Agric Food Chem 56, 9740-9749.

12. Glits $\varnothing$ LV, Gruppen H, Schols HA, et al. (1999) Degradation of rye arabinoxylans in the large intestine of pigs. J Sci Food Agr 79, 961-969.
13. Low AG, Rainbird AL \& Gurr MI (1982) Animal models for studying the effect of fibre on gastrointestinal function. J Plant Foods 4, 29-32.

14. Bach Knudsen KE (1992) Methodological aspects of in vivo methods for measuring of starch digestibility: animal models. In Report of the European Flair Concerted Action Workshop (EURESTA contract no. AGRF/0027), 10-12 November 1991, pp. 40-54 [E Gudmand-Høyer, editor]. Velbaek, Copenhagen, Denmark.

15. Hansen B (1989) Determination of nitrogen as elementary N, an alternative to Kjeldahl. Acta Agric Scand 39, 113-118.

16. Association of Official Analytical Chemists (1990) Euglycemic hyperinsulinemic clamp to assess posthepatic glucose appearance after carbohydrate loading. 2. Evaluation of corn and mung bean starches in healthy men. Official Methods of Analysis. Washington, DC: AOAC.

17. Lauridsen C, Christensen TB, Halekoh U, et al. (2007) Alternative fat sources to animal fat for pigs. Lipid Tech 19, 156-159.

18. Schürch AF, Lloyd LE \& Crampton EW (1950) The use of chromic oxide as an index for determining the digestibility of a diet. $J$ Nutr 50, 629-636.

19. Jensen MT, Cox RP \& Jensen BB (1995) Microbial production of skatole in the hind gut of pigs fed different diets and in relation to skatole deposition in backfat. Anim Sci 61, 293-304.

20. McCleary BV \& Glennie-Holmes M (1985) Enzymatic quantification of (1-3), (1-4)- $\beta$-D-glucan in barley and malt. $J$ Inst Brew 91, 285-295.

21. Theander O, Aman P, Westerlund E, et al. (1994) Enzymatic/ chemical analysis of dietary fiber. J AOAC Int 77, 703-709.

22. Englyst HN, Wiggins HS \& Cummings JH (1982) Determination of the non-starch polysaccharides in plant foods by gas-liquid chromatography of constituent sugars as alditol acetates. Analyst 107, 307-318.

23. Johansen HN, Bach Knudsen KE, Wood PJ, et al. (1997) Physico-chemical properties and the degradation of oat bran polysaccharides in the gut of pigs. J Sci Food Agr 73, 81-92.

24. Canibe N \& Bach Knudsen KE (2002) Degradation and physicochemical changes of barley and pea fibre along the gastrointestinal tract of pigs. J Sci Food Agr 82, 27-39.

25. Wilfart A, Montagne L, Simmins H, et al. (2007) Digesta transit in different segments of the gastrointestinal tract of pigs as affected by insoluble fibre supplied by wheat bran. $\mathrm{Br} J \mathrm{Nutr}$ 98, 54-62.

26. Jansman AJM, Smink W, van Leeuwen P, et al. (2002) Evaluation through literature data of the amount and amino acid composition of basal endogenous crude protein at the terminal ileum of pigs. Anim Feed Sci Technol 98, 49-60.

27. Graham H, Hesselman K \& Aman P (1986) The influence of wheat bran and sugar-beet pulp on the digestibility of dietary components in a cereal-based pig diet. J Nutr 116, 242-251.

28. Bach Knudsen KE \& Jørgensen H (2007) Impact of wheat and oat polysaccharides provided as rolls on the digestion and absorption processes in the small intestine of pigs. $J$ Sci Food Agr 87, 2399-2408.

29. Bach Knudsen KE \& Hansen I (1991) Gastrointestinal implications in pigs of wheat and oat fractions. 1. Digestibility and bulking properties of polysaccharides and other major constituents. Br J Nutr 65, 217-232.

30. Nyman M, Siljestrom M, Pedersen B, et al. (1984) Dietary fiber content and composition in six cereals at different extraction rates. Cereal Chem 61, 14-19.

31. Henry RJ (1987) Pentosan and (1-3), (1-4)-, 1-glucan concentrations in endosperm and whole grain of wheat, barley, oats and rye. J Cereal Sci 6, 253-258.

32. Carpita N \& Gibeaut D (1993) Structural models of primary cell walls in flowering plants: consistency of molecular structure 
with the physical properties of the walls during growth. Plant $J$ 3, 1-30.

33. Leisola MSA \& Garcia S (1989) The mechanisms of lignin degradation. Enzyme Systems for Lignocellulose Degradation, pp. 89-99 [MP Coughlan, editor]. Amsterdam: Elsevier Applied Science.

34. Selvendran RR (1984) The plant cell wall as a source of dietary fiber: chemistry and structure. Am J Clin Nutr 39, 320-337.

35. Bach Knudsen KE, Jensen BB \& Hansen I (1993) Oat bran but not a $\beta$-glucan-enriched oat fraction enhances butyrate production in the large intestine of pigs. $J$ Nutr 123, 1235-1247.

36. Juntunen KS, Laaksonen DE, Autio K, et al. (2003) Structural differences between rye and wheat breads but not total fiber content may explain the lower postprandial insulin response to rye bread. Am J Clin Nutr 78, 957-964.

37. Bach Knudsen KE \& Canibe N (2000) Breakdown of plant carbohydrates in the digestive tract of pigs fed on wheat- or oat-based rolls. J Sci Food Agr 80, 1253-1261.

38. Bach Knudsen KE, Serena A, Bjørnbak Kjaer AK, et al. (2005) Rye bread enhances the production and plasma concentration of butyrate but not the plasma concentrations of glucose and insulin in pigs. $J$ Nutr 135, 1696-1704.

39. Laerke HN, Pedersen C, Mortensen MA, et al. (2008) Rye bread reduces plasma cholesterol levels in hypercholesterolaemic pigs when compared to wheat at similar dietary fibre level. $J$ Sci Food Agr 88, 1385-1393.
40. Edwards CA, Blackburn NA, Craigen L, et al. (1987) Viscosity of food gums determined in vitro related to their hypoglycemic actions. Am J Clin Nutr 46, 72-77.

41. Owusu-Asiedu A, Patience JF, Laarveld B, et al. (2006) Effects of guar gum and cellulose on digesta passage rate, ileal microbial populations, energy and protein digestibility, and performance of grower pigs. J Anim Sci 84, 843-852.

42. Adam A, Levrat-Verny MA, Lopez HW, et al. (2001) Whole wheat and triticale flours with differing viscosities stimulate cecal fermentations and lower plasma and hepatic lipids in rats. J Nutr 131, 1770-1776.

43. Bach Knudsen KE, Jensen BB \& Hansen I (1993) Digestion of polysaccharides and other major components in the small and large intestine of pigs fed on diets consisting of oat fractions rich in $\beta$-D-glucan. Br J Nutr 70, 537-556.

44. Glits $\varnothing$ LV, Jensen BB \& Bach Knudsen KE (2000) In vitro fermentation of rye carbohydrates including arabinoxylans of different structure. J Sci Food Agr 80, 1211-1218.

45. Jensen BB \& Jørgensen H (1994) Effect of dietary fiber on microbial activity and microbial gas production in various regions of the gastrointestinal tract of pigs. Appl Environ Microb 60, 1897-1904.

46. Salvador V, Cherbut C, Barry JL, et al. (1993) Sugar composition of dietary fibre and short-chain fatty acid production during in vitro fermentation by human bacteria. Br J Nutr 70, 189-197. 